\begin{tabular}{|c|l|}
\hline Title & $\begin{array}{l}\text { Development of a mouse monoclonal antibody against the chondroitin sulfate protein linkage region derived from shark } \\
\text { cartilage }\end{array}$ \\
\hline Author(s) & $\begin{array}{l}\text { A katsu, Chizuru; Fongmoon, Duriya; Mizumoto, Shuji; Jacquinet, Jean-Claude; Kongtawelert, Prachya; Y amada, } \\
\text { Shuhei; Sugahara, Kazuy uki }\end{array}$ \\
\hline Citation & $\begin{array}{l}\text { Glycoconjugate Journal, 27(4), 387-399 } \\
\text { https://doi.org/40.1007/310719-010-9286-1 }\end{array}$ \\
\hline Issue Date & 2010-05 \\
\hline Doc URL & http://hdl.handle.net/2115/49189 \\
\hline Rights & The final publication is available at www.springerlink.com \\
\hline Type & article (author version) \\
\hline File Information & GJ27-4_387-399.pdf \\
\hline
\end{tabular}

Instructions for use 


\title{
Development of a mouse monoclonal antibody against the chondroitin sulfate-protein linkage region derived from shark cartilage
}

Chizuru Akatsu, Duriya Fongmoon, Shuji Mizumoto, Jean-Claude Jacquinet, Prachya Kongtawelert, Shuhei Yamada, and Kazuyuki Sugahara

\begin{abstract}
Glycosaminoglycans (GAGs) like chondroitin sulfate (CS) and heparan sulfate (HS) are synthesized on the tetrasaccharide linkage region, GlcA $\beta 1-3 \mathrm{Gal} \beta 1-3 \mathrm{Gal} \beta 1-4 \mathrm{Xyl} \beta 1-O-S e r$, of proteoglycans. The Xyl can be modified by 2-O-phosphate in both CS and HS, whereas the Gal residues can be sulfated at C-4 and/or C-6 in CS but not in HS. To study the roles of these modifications, monoclonal antibodies were developed against linkage glycopeptides of shark cartilage CS proteoglycans, and one was characterized in detail. This antibody bound hexa- and pentasaccharide-peptides more strongly than tetrasaccharide-peptides, suggesting the importance of GalNAc. It did not react to the CS linkage region modified by $4-O$-sulfation. Its reactivity was not affected by treatment with chondro-4-sulfatase or alkaline phosphatase. The results of an ELISA using various proteoglycans and glycopeptides with different modifications suggested the recognition of 6-O-sulfate on the GalNAc and/or Gal residues. Treatments with exopeptidases did not affect the reactivity of the hexasaccharide-peptide fraction, whereas weak alkali to cleave the
\end{abstract}


Xyl-Ser linkage completely abolished the binding activity, suggesting the importance of the Xy-Ser

linkage for the binding. Furthermore, the antibody stained wild-type $\mathrm{CHO}$ cells, but not mutant cells deficient in xylosyltransferase required for the synthesis of the linkage region. These results suggest that the antibody recognizes the structure GalNAc-GlcA-Gal-Gal-Xyl-Ser that is modified by 6-O-sulfation on GalNAc and/or Gal. The antibody will be a useful tool for investigating the significance of the linkage region in the biosynthesis and/or intracellular transport of different GAG chains.

Keywords Proteoglycans, Glycosaminoglycans, Chondroitin sulfate, Heparan sulfate, Dermatan sulfate, Monoclonal antibody

\begin{abstract}
Abbreviations
2AB, 2-aminobenzamide; BSA, bovine serum albumin; CS, chondroitin sulfate; DS, dermatan sulfate; ELISA, enzyme-linked immunosorbent assay; GAG, glycosaminoglycan; Gal, D-galactose; GalNAc, $N$-acetyl-D-galactosamine; GlcA, D-glucuronic acid; GlcN, D-glucosamine; GlcNAc, $N$-acetyl-D-glucosamine; Hep, Heparin; $\quad \Delta$ HexA, 4,5-unsaturated hexuronic acid or 4-deoxy- $\alpha$-L-threo-hex-4-enepyranosyluronic acid; HPLC, high performance liquid chromatography; HS, heparan sulfate; IdoA, L-iduronic acid; PG, proteoglycan; Xyl, D-xylose.
\end{abstract}




\section{Introduction}

Proteoglycans (PGs) are macromolecules composed of linear polysaccharide glycosaminoglycan (GAG) side chains, which are covalently attached to specific Ser residues of core proteins. PGs are distributed mainly in extracellular matrices and at cell surfaces, and implicated in many pathophysiological phenomena. Characteristic GAG moieties appear to play important roles as regulators of various biological processes by interacting with functional protein ligands such as growth factors, cytokines, and morphogens [1-4].

GAGs include chondroitin sulfate/dermatan sulfate (CS/DS) and heparan sulfate/heparin (HS/Hep), which are classified as galactosaminoglycans and glucosaminoglycans, respectively. CS/DS and HS/Hep consist of repeating disaccharide units, GlcA/IdoA-GalNAc and GlcA/IdoA-GlcN/GlcNAc, respectively. GlcA, IdoA, GalNAc, GlcN, and GlcNAc represent D-glucuronic acid, L-iduronic acid, $N$-acetyl-D-galactosamine, D-glucosamine, and $N$-acetyl-D-glucosamine, respectively. GAGs are specifically modified most notably by sulfation at various positions, forming a variety of structures and acquiring functions. Although the structure of the repeating disaccharide region differs between CS/DS and HS/Hep, both types of GAGs are covalently bound to core proteins through the common linkage region tetrasaccharide, GlcA $\beta 1-3 G a l \beta 1-3 G a l \beta 1-4 X y l$ [5], where Gal and Xyl stand for D-galactose and D-xylose, respectively.

In the biosynthesis of GAGs, monosaccharide residues are transferred stepwise from the 
corresponding nucleotide sugars to growing GAG chains, being governed largely by the substrate specificity of the glycosyltransferases involved. This process is initiated by the addition of Xyl to specific serine residues in the core protein, followed by the sequential addition of two Gal residues and a GlcA residue to construct the tetrasaccharide linkage structure [1]. The synthesis of CS/DS chains initiates once GalNAc is transferred by the $N$-acetylgalactosaminyltransferase-I (GalNAcT-I) activity of chondroitin synthases to the GlcA of the common linkage region, whereas that of HS/Hep chains initiates if GlcNAc is first added by the $N$-acetylglucosaminyltransferase-I (GlcNAcT-I) activity $[1,4,6]$. Hence, GalNAcT-I and GlcNAcT-I activities are crucial for the determination of the GAG species to be synthesized on the common tetrasaccharide linkage region. However, it is not clear how these different GAGs are selectively assembled on the common structure.

We have carried out a series of structural studies of the GAG-protein linkage region, based on the working hypothesis that there may be differences in the region's structure among GAG chains and such differences may contribute to the determination of the type and/or character of the GAG species to be synthesized [6,7]. These structural studies have revealed unique modifications, such as 4-O-sulfated Gal, 6-O-sulfated Gal, and 2-O-phosphorylated Xyl. So far, sulfated Gal residues have been demonstrated only in the linkage region of CS/DS, not in HS/Hep, though a 2-O-phosphorylated Xyl residue has been found in both CS/DS and HS/Hep [6, 8, 9], suggesting the sulfate groups on the Gal residues to be involved in the selective assembly of different GAG types. In fact, it has been demonstrated that these modifications influence the catalytic activities of 
galactosyltransferase-I, which transfers Gal-2 (for the numbering of the sugar residues, see Table 1), and glucuronyltransferase-I (GlcAT-I), which transfers the first GlcA, involved in the construction of the tetrasaccharide linkage region $[10,11]$. However, it is not fully understood if these modifications also affect on other biosynthetic enzymes or play a biological role as recognition signals for regulatory proteins such as intracellular transporters.

The use of antibodies has become a standard approach in many fields of biochemical and biomedical research. To clarify the biological significance of the modifications in the GAG-protein linkage region, antibodies which recognize specific patterns of modification in the region may be useful. Monoclonal antibodies (mAbs) that recognize specific features of the repeating disaccharide region of CS chains have been generated, and epitopes of some of them have been characterized [12-16]. Studies using anti-CS mAbs have revealed restricted spatiotemporal patterns of the expression of specific CS structures in various tissues during growth and development, and in pathological conditions [16-19]. However, so far, no antibodies have been reported which recognize the GAG-protein linkage region. In the present study, a mAb against the CS-protein linkage region from shark cartilage was developed and its epitope was characterized.

\section{Materials and methods}

Materials PGs from salmon nasal cartilage, chicken cartilage, and whale cartilage were provided by Biomatec Japan Inc. (Kushiro, Japan). PG from rayfish cartilage was obtained from Marukyou 
Biofoods Co., Ltd. (Kushiro, Japan). PG from birds' nests made with dried saliva of male Collocalia swiftlets was provided by Y. T. Li, Tulane University [20]. PG from bovine nasal cartilage was a gift from the late Dr. Albert Dorfman, University of Chicago. A whale cartilage CS-peptide fraction, which contained Ser, Asp, Thr, Glu, Pro, Gly, Ala, Val, Lys and Arg in a molar ratio of $1.00: 1.74$ : $0.42: 1.99: 1.53: 4.22: 1.00: 0.52: 0.63: 0.65$, was prepared as reported [21].

The following enzymes were purchased from Seikagaku Corp. (Tokyo, Japan): chondroitinase (CSase) ABC (EC 4.2.2.20) from Proteus vulgaris, CSase AC-I (EC 4.2.2.5) from Fravobacterium heparinum, CSase AC-II (EC 4.2.2.5) from Artherobacter aurescens, and chondro-4-sulfatase (EC 3.1.6.9) from P. vulgaris. Aminopepitidase M (EC 3.4.11.2) from porcine kidney, carboxypeptidase Y (EC 3.4.16.5) from yeast, and calf intestinal alkaline phosphatase (EC 3.1.3.1) of special quality for molecular biology were obtained from EMD Biosciences, Inc. (San Diego, CA), Oriental Yeast Co., Ltd. (Tokyo, Japan), and Boehringer Mannheim GmbH (Mannheim, Germany), respectively. Anti-HS antibody F58-10E4 and Alexa Fluor $488^{\circledR}$-labeled goat anti-mouse IgM antibody were purchased from Seikagaku Corp. (Tokyo, Japan) and Molecular Probes (Eugene, OR), respectively. Synthetic peptides, Leu-p-nitroanilide and benzyloxycarbonylglycyl-Phe, were purchased from Wako Pure Chemical Industries, Ltd. (Osaka, Japan) and Peptide Institute, Inc. (Osaka, Japan), respectively.

Wild-type Chinese hamster ovary (CHO) cells (CHO-K1) and xylosyltransferase-deficient CHO cells (pgsA-745) [22] were purchased from American Type Culture Collection (Manassas, VA). 
These cell lines were maintained in Ham's F12K medium (Wako Pure Chemical Industries, Ltd., Osaka, Japan) supplemented with $10 \%$ heat-inactivated fetal bovine serum at $37{ }^{\circ} \mathrm{C}$ in a humidified atmosphere containing $5 \% \mathrm{CO}_{2}$.

$\begin{array}{llll}\text { The } & \text { Structurally } & \text { defined } & \text { linkage }\end{array}$ $\Delta$ HexA-GalNAc(4-O-sulfate)-GlcA-Gal(4-O-sulfate)-Gal-Xyl was isolated from whale cartilage CS-PG [23]. $\quad$ HexA stands for 4,5-unsaturated hexuronic acid. A 2-aminobenzamide (2AB)-derivative of the linkage hexasaccharide $\Delta$ HexA-GalNAc-GlcA-Gal-Gal-Xyl(2-O-phosphate)-2AB, was prepared as described previously [23]. The tetrasaccharide peptide GlcA-Gal-Gal-Xyl(2-O-phosphate)-Ser-Gly was chemically synthesized [24].

Preparation of the oligosaccharide-peptides from the CS-core protein linkage region The CS-peptide fraction $(1.0 \mathrm{~g})$ was prepared from shark cartilage $[25,26]$ and exhaustively digested with $1.2 \mathrm{IU}$ of CSase $\mathrm{ABC}$ in a total volume of $12.5 \mathrm{ml}$ of $50 \mathrm{mM}$ Tris/HCl buffer, $\mathrm{pH} 8.0$, containing $60 \mathrm{mM}$ sodium acetate and $0.1 \%$ bovine serum albumin (BSA) for $25 \mathrm{~h}$ at $37^{\circ} \mathrm{C}$. An additional $0.2 \mathrm{IU}$ of the enzyme was added after $23 \mathrm{~h}$ to complete the digestion, and the reaction was terminated by heating at $100{ }^{\circ} \mathrm{C}$ for $5 \mathrm{~min}$. The digest was fractionated by gel filtration using a column $(2.0 \times 149 \mathrm{~cm})$ of Sephadex G-15 (GE Healthcare, Buckinghamshire, UK) with $0.25 \mathrm{M} \mathrm{NH}_{4} \mathrm{HCO}_{3} / 7 \%$ 1-propanol as the eluent. The isolated linkage hexasaccharide-peptide fraction was digested with CSase ABC again 
as described above to complete the digestion, and this process was repeated three times until no disaccharide was produced as judged by gel filtration chromatography. This fraction contained several amino acids including Ser, Glu, Pro, Gly, Val, and Lys in a molar ratio of 1.00, 1.16, 1.41, $1.23,0.46$, and 0.29 , respectively [25].

To eliminate the $\Delta$ HexA residue, which has strong immunogenic activity, from the nonreducing end of the linkage hexasccharide-peptides, the glycopeptides were treated with mercuric acetate as described previously $[27,28]$. Namely, the linkage hexasaccharide-peptide fraction (1.5 $\mu \mathrm{mol}$ as linkage hexasaccharide) was treated with $0.2 \mathrm{ml}$ of $10 \mathrm{mM}$ mercuric acetate in $130 \mathrm{mM}$ sodium acetate buffer, $\mathrm{pH} 5.0$, overnight at room temperature. After the addition of $2 \mathrm{ml}$ of $5 \mathrm{M} \mathrm{NaCl}$, the reaction mixture was desalted by successive gel filtration using a Sephadex G-25 (fine) column (1.5 X $47 \mathrm{~cm}$ ) equilibrated with $1 \mathrm{M} \mathrm{NaCl}$ and then with $\mathrm{H}_{2} \mathrm{O}$.

The linkage tetrasaccahride-peptides were prepared by treatment of the linkage hexasaccharide-peptides (120 nmol as $\Delta \mathrm{HexA}$ ) with $10 \mathrm{mIU}$ of CSase AC-I [29] in a total volume of $30 \mu \mathrm{l}$ of $50 \mathrm{mM}$ of Tris/ $\mathrm{HCl}$ buffer, $\mathrm{pH} 7.3$, at $37^{\circ} \mathrm{C}$ for $20 \mathrm{~h}$. The enzymatic reaction was terminated by heating at $95^{\circ} \mathrm{C}$ for $1 \mathrm{~min}$.

The linkage oligosaccharide-peptide fraction was treated with $\mathrm{LiOH}$ as described below to release the oligosaccharide from the core peptides, labeled with $2 \mathrm{AB}$ and analyzed by anion exchange HPLC on an amine-bound silica PA-03 column (4.6 X 250 mm, YMC Co., Kyoto, Japan) to confirm the presence of the linkage oligosaccharide components predicted. The molar 
concentration of the linkage oligosaccharide-peptides was determined by measuring absorbance at $232 \mathrm{~nm}$ based on an average millimolar absorption coefficient of 5.5 for the double bond of $\Delta \mathrm{HexA}$ [30] or by the carbazole reaction to measure uronic acids (GlcA and $\Delta \mathrm{HexA}$ ) colorimetrically [31].

Production of the monoclonal antibody Monoclonal antibodies were generated by immunizing BALB/c mice with the linkage pentasaccharide-peptide fraction from shark cartilage CS. The linkage pentasaccharide-peptide fraction was conjugated with a carrier protein, keyhole limpet hemocyanin (KLH) (Sigma, St Louis, MO), using glutaraldehyde [32], which cross-links primary amino groups of peptides as described below: $1 \mu \mathrm{mol}$ of the fraction was conjugated with $4 \mathrm{mg}$ of $\mathrm{KLH}$ in $2 \mathrm{ml}$ of phosphate-buffered saline (PBS), $\mathrm{pH} 7.2$, with the addition of glutaraldehyde to a final concentration of $0.1 \%$ at room temperature overnight. The reaction was terminated by addition of $0.25 \mathrm{ml}$ of $1 \mathrm{M}$ glycine, and then the conjugates were dialyzed overnight against PBS. The KLH-conjugated linkage pentasaccharide-peptide fraction was injected into mice at $20 \mu \mathrm{g} / \mathrm{injection}$ every 2 weeks. After the fourth injection, the serum was screened for reactivity with the linkage hexasaccharide-peptides. Spleen B lymphocytes of the positive mice were isolated and fused with myeloma cells. The culture supernatant of the fused hybridoma cells was screened by enzyme-linked immunosorbent assay (ELISA) using the linkage hexasaccharide-peptides, and three positive clones, 4E1, 3F11, and 1B5, were selected. The clone $4 \mathrm{E} 1$ with the highest specificity toward the linkage hexasaccharide-peptide fractions was recloned, and eleven secondary clones were further selected. Among the eleven clones, 
six showed high specificity and were injected intraperitoneally into mice to obtain ascitic fluid. Antibody subclasses were determined using the ImmunoPure ${ }^{\circledR}$ Monoclonal Antibody Isotyping Kit II (Pierce Biotechnology, Rockford, IL). The mAb 4E1/D6 was of particular interest because of its specific activity, and subsequently characterized in detail.

ELISA The specificity of the antibody 4E1/D6 in terms of antigen recognition was tested by ELISA. Briefly, various PG preparations or linkage oligosaccharide-peptide fractions $(0.5 \mu \mathrm{g}$ each) were dissolved in a $0.2 \mathrm{M}$ sodium bicarbonate buffer, $\mathrm{pH} 9.6$ and individually immobilized overnight to a 96-well microtiter plate (Nunc immune plate, MaxiSorp, Nalge Nunc International, Rochester, NY) at room temperature. The wells were washed once with PBS, $\mathrm{pH} 7.4$, containing $0.05 \%$ Tween 20 (PBST), and blocked with 3\% (w/v) BSA in PBS for $1 \mathrm{~h}$ at $37^{\circ} \mathrm{C}$. The wells were then washed with PBST once and incubated with 4E1/D6 for $2 \mathrm{~h}$ at $37{ }^{\circ} \mathrm{C}$. After three washes with $25 \mathrm{mM}$ Tris-buffered saline (TBS) containing 0.05\% Tween20 (TBST), the wells were incubated with alkaline phosphatase-labeled anti-mouse $\operatorname{Ig}(\mathrm{G}+\mathrm{M})$ (3,000-fold dilution, Chemicon, San Diego, CA). Enzymatic activity was detected using $p$-nitrophenylphosphate by measuring the absorbance at 415 nm.

For the competitive ELISA, aliquots of the linkage hexasaccharide-peptides from shark cartilage CS, which had been pretreated with peptidase or $\mathrm{LiOH}$, was incubated with 4E1/D6 in a total volume of $50 \mu \mathrm{L}$ at $37^{\circ} \mathrm{C}$ for $1 \mathrm{~h}$, then the mixture was applied to the wells where untreated 
linkage hexasaccharide-peptides from shark cartilage CS had been immobilized. The color was developed as described above.

Chemical and enzymatic treatments of the linkage hexasaccharide-peptide fraction To liberate $O$-linked linkage oligosaccharides from the core peptides, treatment with $\mathrm{LiOH}$ was performed as described previously [23, 33]. Briefly, the hexasaccharide-peptide fraction (183 nmol) was treated with $0.5 \mathrm{M} \mathrm{LiOH}$ at $4^{\circ} \mathrm{C}$ for $15 \mathrm{~h}$. The reaction was terminated by neutralization with $2.0 \mathrm{M}$ acetic acid, and then $\mathrm{Li}^{+}$was removed by cation-exchange chromatography using AG 50W-X2 resin (Bio-Rad Laboratories, Hercules, CA).

Aminopeptidase $\mathrm{M}$ or carboxypeptidase $\mathrm{Y}$ digestion was carried out using $10 \mathrm{nmol}$ of the linkage hexasaccharide-peptide fraction and $3 \mathrm{U}$ of each enzyme in $10 \mu \mathrm{l}$ of $25 \mathrm{mM}$ immidazole/ $\mathrm{HCl}$ buffer, $\mathrm{pH}$ 7.6, or $50 \mathrm{mM}$ phosphate buffer, $\mathrm{pH} 6.0$, respectively, for $30 \mathrm{~min}$ at $37^{\circ} \mathrm{C}$.

To investigate the reactivity of the antibody 4E1/D6 to the 4-O-sulfated or 2-O-phosphorylated linkage structure, treatment with chondro-4-sulfatase or alkaline phosphatase was conducted. One nmol of the linkage hexasaccharide-peptide fraction or a structurally defined linkage hexasaccharide, $\Delta$ HexA-GalNAc(4- $O$-sulfate)-GlcA-Gal(4- $O$-sulfate)-Gal-Xyl, was digested with the indicated enzyme. Digestion with chondro-4-sulfatase was performed with $12 \mathrm{mIU}$ of the enzyme for $6 \mathrm{~h}$ in $3 \mu \mathrm{L}$ of $50 \mathrm{mM}$ Tris/ $\mathrm{HCl}$ buffer, $\mathrm{pH} 7.5$, containing $50 \mathrm{mM}$ sodium acetate [34]. Treatment with alkaline phosphatase was carried out with 1 IU of the enzyme in a total volume of 3 
$\mu \mathrm{L}$ of the buffer supplied by the manufacturer at $37^{\circ} \mathrm{C}$ for $6 \mathrm{~h}$.

Immunofluorescence flow cytometry $\mathrm{CHO}-\mathrm{K} 1$ and pgsA-745 cells were detached with $2 \mathrm{mM}$ EDTA and suspended in PBS containing 0.1\% BSA (PBS-BSA) at a concentration of $10^{6}$ cells $/ \mathrm{ml}$. After three washes with PBS-BSA, the cells were incubated with the antibody 4E1/D6 (400-fold dilution) or a commercial antibody F58-10E4 against $\mathrm{HS}$ (200-fold dilution) at $4^{\circ} \mathrm{C}$ for $30 \mathrm{~min}$. The cells were washed with PBS-BSA three times and incubated with Alexa Fluor $488^{\circledR}$-labeled goat anti-mouse IgM antibody (500-fold dilution). After three washes with PBS-BSA, the cells were analyzed by immunofluorescence flow cytometry in a BD FACSCanto (BD Biosciences, San Jose, CA). Flow cytometric data were analyzed using Flowjo software (Tree Star, Inc., Ashland, OR).

\section{Results}

Production of the monoclonal antibody against the linkage oligosaccharide-peptide fraction of shark cartilage CS The CS-peptide fraction of shark cartilage was exhaustively digested with CSase ABC to prepare the linkage hexasaccharide-peptide fraction. Approximately $9.2 \mu \mathrm{mol}$ of this fraction was obtained and an aliquot was analyzed by anion-exchange HPLC on an amine-bound silica PA-03 column after cleavage of the bond between the xylose and the serine using $\mathrm{LiOH}[23,33]$ (results not shown). The fraction contained at least thirteen hexasaccharide compounds as reported (Table 1) [25, 26]. Since the glycopeptides contain a $\Delta \mathrm{HexA}$ residue at the nonreducing terminus, which is an 
unnatural structure causing strong antigenicity, the $\Delta \mathrm{Hex} A$ residue was eliminated by treatment with mercuric acetate $[27,28]$. The pentasaccharide-peptide fraction was conjugated with KLH and used as an immunogen to develop mAbs against the CS-core protein linkage region.

After immunization of $\mathrm{BALB} / \mathrm{c}$ mice with the immunogen, six positive clones were obtained by screening assays using the CS hexasaccharide-peptide fraction immobilized onto a Nunc Maxisorp plate. Clone 4E1/D6, with the highest level of activity, was characterized further. This clone contained an IgM-type immunoglobulin with kappa light chains (data not shown), and the concentration of protein in ascitic fluid was $34.3 \mathrm{mg} / \mathrm{ml}$ as determined using the BCA protein assay kit according to the instructions provided by the manufacturer (Thermo Scientific, Rockford, IL).

Assessment of the reactivity of the antibody 4E1/D6 toward various PGs To characterize the specificity of 4E1/D6, the antibody's reactivity toward various PGs was assessed by ELISA (Fig. 1), where PGs were individually immobilized onto a Nunc Maxisorp plate through their protein moiety. The linkage hexasaccharide-peptide fraction from shark cartilage CS was also immobilized as a positive control. Significant binding of 4E1/D6 was observed with the linkage hexasaccharide fraction and a PG from salmon nasal cartilage, but with no other PGs tested. The reactivity of 4E1/D6 toward this PG was confirmed by a competitive ELISA: a soluble PG from salmon nasal cartilage inhibited the binding of 4E1/D6 to the immobilized linkage hexasacchairde-peptide fraction of shark cartilage CS in a dose-dependent manner (data not shown). 4E1/D6 reacted less extensively 
to the salmon PG than the linkage hexasaccharide-peptide fraction and not at all to the other PGs tested. Of course, the possibility exists that the linkage regions of these PGs are masked by CS polysaccharide side chains, and so are inaccessible to the antibody. However, the structural difference among these PGs remains investigated.

Assessment of the reactivity of 4E1/D6 toward the linkage region oligosaccharides To investigate the structural features of the linkage pentasaccharide-peptides required for recognition by 4E1/D6, the reactivity of 4E1/D6 toward linkage hexa-, penta-, and tetrasaccharide-peptide fractions of shark cartilage CS was assessed by ELISA (Fig. 2). The linkage tetrasaccharide-peptide fraction was prepared by digestion of the linkage hexasaccharide-peptide fraction with CSase AC-I, and the exhaustive digestion was confirmed by gel filtration chromatography of the digest. The linkage hexa-, penta-, and tetrasaccharide-peptide fractions $(0.5 \mu \mathrm{g}$ each) were immobilized onto Maxisorp plates. The reactivity was considerably weaker toward the tetrasaccharide-peptides than hexa- or pentasaccharide-peptides of shark cartilage CS (Table 1). These results suggest the fifth saccharide residue GalNAc-5 in the linkage oligosaccharide-peptide fraction to be important for recognition by 4E1/D6. In strong contrast, the hexasaccharide-peptide fraction of whale cartilage CS, which contains four major saccharide sequences with different sulfation patterns (Table 1), showed no reactivity, suggesting that the 4E1/D6 epitope may contain a particular modification in the linkage region. In addition, 4E1/D6 may distinguish the different amino acid sequences in the peptide moiety 
of the linkage oligosaccharide-peptide of shark cartilage CS from those of whale cartilage CS (see above).

Assessment of the reactivity of 4E1/D6 toward the peptide moiety of the linkage hexasaccharide-peptides To assess whether 4E1/D6 recognizes the peptide moiety of the linkage hexasaccharide-peptides, a competitive ELISA was carried out using the linkage hexasaccharide fraction from shark cartilage $\mathrm{CS}$ treated with $\mathrm{LiOH}$, aminopeptidase, or carboxypeptidase as an inhibitor (Fig. 3). Treatment with $\mathrm{LiOH}$ liberates hexasaccharides from the core peptide. Upon treatment with aminopeptidase or carboxypeptidase, amino acid residues located on the amino or carboxy terminal side of the Ser residue are trimmed, respectively. The LiOH-treated sample did not inhibit at all the binding of 4E1/D6 to the linkage hexasaccharide-peptides of shark cartilage CS. In contrast, the digest of the linkage hexasaccharide fraction obtained with aminopeptidase or carboxypeptidase inhibited the binding of 4E1/D6 to the un-treated linkage hexasaccharide-peptide to a comparable degree with the linkage hexasaccharide-peptides of shark cartilage CS (Fig. 3). The activities of aminopeptidase and carboxypeptidase were confirmed by colorimetric assays using the artificial substrates Leu-p-nitroanilide and benzyloxycarbonylglycyl-Phe, respectively [35, 36]. From these results, 4E1/D6 does not appear to recognize sequences composed of multiple amino acids. Rather, the xylosidic linkage to the Ser residue appears to be recognized by 4E1/D6. The possibility exists that a few amino acids immediately adjacent to the Ser residue are also recognized since in 
amino acid composition, the hexasaccharide peptide fractions derived from shark and whale cartilage CS differ considerably (see above).

Assessment of the reactivity of 4E1/D6 to the sulfatase- or phosphatase-treated linkage hexasaccharide-peptide fraction Since 4E1/D6 did not react to the hexasaccharide-peptide fraction of whale cartilage CS (Fig. 2), it seems to recognize a sulfated or phosphorylated component of the pentasaccharide-peptide fraction of shark cartilage CS. GalNAc and two Gal residues can often be modified by $6-O$-sulfate, and $\mathrm{Xyl}$ can be modified by $2-O$-phosphate. In addition, GalNAc-5 and Gal-3 can be sulfated at position C-4. Therefore, to examine whether 4-O-sulfation and 2-O-phosphorylation in the linkage region are required for the epitope's recognition, the reactivity of 4E1/D6 toward the linkage hexasaccharide-peptide fraction was investigated by ELISA before and after digestion with chondro-4-sulfatase or alkaline phosphatase (Fig. 4). The reactivity of 4E1/D6 toward the hexasaccharide-peptide fraction was not diminished after either treatment, suggesting that neither the 4-O-sulfate nor 2-O-phosphate group is recognized by 4E1/D6. The enzymatic activity of chondro-4-sulfatase and alkaline phosphatase toward the linkage region was confirmed by digestion of the structurally defined linkage hexasaccharides. As shown in Fig. 5, after treatment with chondro-4-sulfatase, the position of the disulfated linkage hexasaccharide $\Delta$ HexA-GalNAc(4-O-sulfate)-GlcA-Gal(4-O-sulfate)-Gal-Xyl (Fig. 5A, closed arrow) shifted to that position of the nonsulfated linkage hexasaccharide $\Delta$ HexA-GalNAc-GlcA-Gal-Gal-Xyl (Fig. 5B, 
open arrow). Digestion of the 2AB-derivative of the phosphorylated hexasaccharide, $\Delta$ HexA-GalNAc-GlcA-Gal-Gal-Xyl(2-O-phosphate)-2AB, with alkaline phosphatase yielded $\triangle$ HexA-GalNAc-GlcA-Gal-Gal-Xyl-2AB as judged by anion-exchange HPLC (data not shown). The recognition of the 2-O-phosphorylated linkage region by 4E1/D6 was also examined by competitive ELISA using a chemically synthesized linkage tetrasaccharide-peptide, GlcA-Gal-Gal-Xyl(2-O-phosphate)-Ser-Gly [24], as an inhibitor. However, it showed no inhibitory activity. No sulfatase which hydrolyzes 6-O-sulfate groups in the linkage region is available, and therefore it is not possible to investigate whether the 6-O-sulfate groups are recognized. The commercial bacterial chondro-6-sulfatase (Seikagaku Corp.) does not act on the 6-O-sulfate groups of the Gal residues in the linkage region [34].

Analysis of the interactions of 4E1/D6 with CHO cell lines deficient in the biosynthetic enzymes for the linkage region of GAGs The specificity of 4E1/D6 was investigated further by analyzing its interaction with two $\mathrm{CHO}$ cell lines, $\mathrm{CHO}-\mathrm{K} 1$ and pgsA-745, using immunofluorescence flowcytometry. The pgsA-745 is a mutant cell line deficient in xylosyltransferase, and was established from CHO-K1 cells (wild type) [22]. In the biosynthesis of CS and HS, a xylosyltransferase initiates the formation of the tetrasaccharide linkage region by transferring a Xyl residue to a specific Ser residue of the core protein. The pgsA-745 cells produce neither CS nor HS polysaccharide chains since they cannot construct the linkage region, which is common to CS and 
HS. Although no immunoreactivity with pgsA-745 cells was detected (Fig. 7B, light gray histograms), weak but significant immunoreactivity with CHO-K1 cells was (Fig. 7A, light gray histogram), suggesting the epitope of 4E1/D6 to exist on the surface of wild-type CHO cells but not the mutant cells. A HS-specific antibody, F58-10E4, was used as a positive control, and as expected, intensely stained CHO-K1 cells but did not stain pgsA-745 cells (Fig. 7, dark gray histograms).

\section{Discussion}

Galactosaminoglycans (CS/DS) and glucosaminoglycans (HS/Hep) are synthesized at specific Ser residues of the core proteins of PGs through the tetrasaccharide linkage region GlcA $\beta 1-3$ Gal $\beta 1-3 \mathrm{Gal} \beta 1-4 \mathrm{Xyl}$ [5]. Although the tetrasaccharide core is common to CS/DS and HS/Hep, the pattern of modification in the linkage region differs between the two types of GAG chains. Namely, the 4-O-sulfation of a Gal-3 residue and 6-O-sulfation of both Gal-2 and Gal-3 residues have been found in CS/DS, but not HS/Hep. Interestingly, syndecan-1, a hybrid-type PG bearing both HS and CS chains, carries a 4-O-sulfate on the Gal-3 of only the CS chains [9], supporting the notion that $4-O$-sulfation is a modification specific to CS chains [7]. In contrast, phosphorylation occurs on the Xyl of both CS/DS and HS/Hep [9]. Interestingly, these modifications have significant effects on the synthesis of the tetrasaccharide linkage region. The phosphate on Xyl stimulates the attachment of the first GlcA-4 [10, 11], but then seems to be removed [37]. In contrast, it inhibits the attachment of Gal-2 [10], suggesting the phosphorylation to take place after the transfer 
of Gal-2 but before that of GlcA-4. Intriguingly, the sulfation of Gal-2 promotes the transfer of the first GlcA $[10,11]$. Furthermore, prior 4-O-sulfation of Gal-3 stimulates the $6-O$-sulfation of Gal-2 by recombinant human C6ST-1 [38]. Thus, the sulfated linkage region may also contain signals that influence further sulfation of the linkage region and the repeating disaccharide region as well as chain polymerization. In fact, sulfation in the vicinity of the linkage region has an influence on the $\beta-N$-acetylgalactosaminyltransferase activity for chain elongation $[39,40]$. However, the biological significance of modifications to the linkage region has not been fully elucidated, and tools such as antibodies which recognize these modifications are needed.

In this study, a monoclonal antibody, 4E1/D6 (IgM, kappa), which recognizes the CS-protein linkage region derived from CS of shark cartilage, was developed for the first time. It recognizes the core pentasaccharide GalNAc-GlcA-Gal-Gal-Xyl: the linkage between the Xyl and Ser is also essential. A few other amino acids in the vicinity of the Ser residue may be recognized as well. In addition, the fifth sugar residue (GalNAc-5) from the reducing end is also important. The 2-O-phosphate on $\mathrm{Xyl}$ is not involved in the recognition. The antibody did not bind the hexasaccharide glycopeptide fraction $(\Delta$ HexA-GalNAc $( \pm 4-O$-sulfate)-GlcA-Gal( $\pm 4-O$-sulfate)-Gal-Xyl-peptides $)$ prepared from CS of whale cartilage [21], suggesting that it does not recognize the unmodified tetrasaccharide core or 4- $O$-sulfate groups. In contrast, the 6-O-sulfate groups on the GalNAc and/or Gal residues appear to be recognized. The results altogether indicate that the antibody recognizes at least one of the 
following structures isolated from CS of shark cartilage $[25,26]$ :

GalNAc-GlcA-Gal-Gal(6-O-sulfate)-Xyl-Ser,

GalNAc(6-O-sulfate)-GlcA-Gal-Gal(6-O-sulfate)-Xyl-Ser,

GalNAc-GlcA-Gal(6-O-sulfate)-Gal(6-O-sulfate)-Xyl-Ser,

GalNAc(6-O-sulfate)-GlcA-Gal(6-O-sulfate)-Gal(6-O-sulfate)-Xyl-Ser. Although the precise epitope remains unidentified due to the inavailability of specific reagents such as a sulfatase to remove 6-O-sulfate groups, this antibody will still be useful for investigating the biological significance of the 6-O-sulfation of the GalNAc and/or Gal residues of the core pentasaccharide.

The 6-O-sulfated Gal residues in the linkage region have been demonstrated in CS chains isolated from shark cartilage [26], as well as bovine and human articular cartilage [8, 41]. The antibody reacted with the $\mathrm{CHO}-\mathrm{K} 1$ cells as well, suggesting the presence of the structure in the CS chains on the surface of mammalian cells, although it is extremely difficult to determine using a chemical method the structure of a minute part of the linkage region of CS/DS or HS/Hep derived from cultured cells, which contain only one mole per single GAG chain. Notably, however, a recombinant human chondroitin 6-O-sulfotransferase-1 (C6ST-1), which transfers a sulfate to the C-6-position of GalNAc in the repeating disaccharide region of CS chains, can also transfer a sulfate group to both the Gal residues in the linkage region [38]. Likewise, a recombinant human chondroitin 4-O-sulfotransferase-1 (C4ST-1), which transfers a sulfate to the C-4-position of GalNAc in the repeating disaccharide region of CS chains, can also transfer a sulfate group to Gal-3 
in the linkage region (Mizumoto et al., unpublished results). The 4-O-sulfated Gal-3 structure has been shown in CS from various mammalian tissues and cells including rat chondrosarcoma [7] and human plasma [42]. The kinase that phosphorylates the Xyl residue has recently been identified as FAM20B [43]. Thus, the above modifications appear to be widely distributed.

Modifications of the linkage region may also act as a marker for the intracellular transport of CS-PGs to the Golgi compartment for biosynthetic processing or elongation and maturation of the repeating disaccharide region of CS chains. It is likely that PGs modified with a 4-O- or 6-O-sulfate group by the actions of C4ST-1 or C6ST-1 are transported into the suitable Golgi compartment, and consequently sulfated on GalNAc residues for maturation as well. It would be interesting to investigate putative binding proteins, which recognize the sulfated Gal residues and may help acceleration of the transport and/or sulfation of the GalNAc residues of the repeating disaccharide region. Thus, the sulfation of the Gal residues may reflect a possible difference in the Golgi compartments in which CS and HS chains are synthesized.

It should be noted that C6ST-1 activity is found in medial and trans-Golgi fractions [44]. and that GlcAT-I involved in the synthesis of the linkage region is distributed in both medial and trans Golgi/trans Golgi networks. This distribution is similar to that of chondroitin-polymerizing glucuronyltransferase-II activity [45]. It has also been reported that GlcAT-I has a dual Golgi distribution similar to that of chondroitin polymerizing GlcA transferase-II and distinctly different from the distribution of the two galactosyltransferases found exclusively in cis-Golgi fractions [45]. 
It has also been reported that xylosyltransferase, galactosyltransferases, and GlcAT-I are distributed in ER/cis-Golgi, cis-/medial-Golgi, and medial-/trans-Golgi, respectively [46]. These results suggest that nascent PGs are transported from cis- to trans-Golgi compartments during maturation, and that the sulfation of the linkage region takes place before the transfer of the first $\mathrm{N}$-acetylhexosamine residue to the tetrasaccharide core and could be a signal for the differential assembly of CS and HS chains as proposed previously $[7,21,26]$.

The $\mathrm{CHO}$ mutant cells, which are deficient in the glycosyltransferases that synthesize the linkage region tetrasaccharide core, cannot synthesize either CS/DS or HS/Hep, suggesting the same glycosyltransferases synthesize the linkage region common to both types of the GAG chains $[22,47$, 48]. Therefore, the types of GAG chains to be selectively assembled on the linkage region tetrasaccharide are determined after or during the construction of the linkage region by these enzymes. The amino acid sequence around the GAG attachment site (Ser) varies among different PGs. Therefore, it is unlikely that only the amino acid sequence near the GAG attachment site determines the type of GAG, although it has some influence [49]. In fact, a PG named serglycine is a typical example, which can be modified by CS or HS [50].

A number of PGs occur in the form of both a PG and a protein without a GAG chain, and are called part-time PGs [51]. For example, thrombomodulin, a cell surface glycoprotein, occurs both as a CS-PG ( $\beta$-thrombomoduline) and as a protein without a CS chain ( $\alpha$-thrombomodulin), which has only a tetrasaccharide linkage region, being an immature glycoprotein [52]. The biosynthetic 
1 2 3

control mechanism to produce such immature PG forms or to interfere with the glycanation step remains to be investigated. This antibody may also be useful for investigating the biological functions and processing of part-time PGs. 


\section{Acknowledgements}

This work was supported in part by a Grants-in-aid for Scientific Research (B) (20390019) from the

Ministry of Education, Culture, Sports, Science, and Technology of Japan (MEXT), and for Regional

R\&D Proposal-Based Program from Northern Advancement Center for Science \& Technology of

Hokkaido Japan. 


\section{Footnotes}

1. Affiliation of the authors

Chizuru Akatsu ${ }^{1}$, Duriya Fongmoon ${ }^{1,2,3}$, Shuji Mizumoto ${ }^{1}$, Jean-Claude Jacquinet ${ }^{4}$, Prachya Kongtawelert $^{2}$, Shuhei Yamada ${ }^{1, *}$, and Kazuyuki Sugahara ${ }^{1, *}$

(1) Laboratory of Proteoglycan Signaling and Therapeutics, Graduate School of Life Science, Hokkaido University, Frontier Research Center for Post-Genomic Science and Technology, Nishi 11-choume, Kita 21-jo, Kita-ku, Sapporo, Hokkaido 001-0021, Japan

(2) Thailand Excellence Center for Tissue Engineering, Department of Biochemistry, Faculty of Medicine, Chiang Mai University, Chiang Mai 50200, Thailand

(3) Lampang Cancer Center, Department of Medicine, Ministry of Public Health, Lampang 52000, Thailand

(4) Institut de Chimie Organique et Analytique - CNRS UMR 6005, UFR Sciences, Universit d'Orlans, BP 6759, 45067 Orlans Cedex, France

*E-mail: tjohej@sci.hokudai.ac.jp and k-sugar@sci.hokudai.ac.jp 


\section{References}

1. Bishop, J.R., Schuksz, M., Esko, J. D.: Heparan sulphate proteoglycans fine-tune mammalian physiology. Nature 446, 1030-1037 (2007)

2. Sugahara, K., Mikami, T.: Chondroitin/dermatan sulfate in the central nervous system. Curr. Opin. Struct. Biol. 17, 536-545 (2007)

3. Yamada, S., Sugahara, K.: Potential therapeutic application of chondroitin sulfate/dermatan sulfate. Curr. Drug. Discov. Technol. 5, 289-301 (2008)

4. Nadanaka, S., Kitagawa, H.: Heparan sulphate biosynthesis and disease. J. Biochem. 144, 7-14 (2008)

5. Lindahl, U., Rodén, L.: Carbohydrate-protein linkages in proteoglycans of animal, plant and bacterial origin. In: Gottschalk, A. (ed.) Glycoproteins pp. 491-517, Elsevier Science Publishing Co., Inc., New York (1972)

6. Sugahara, K., Kitagawa, H.: Recent advances in the study of the biosynthesis and functions of sulfated glycosaminoglycans. Curr. Opin. Struct. Biol. 10, 518-527 (2000)

7. Sugahara, K., Yamashina, I., de Waard, P., van Halbeek, H., Vliegenthart, J.F.G.: Structural studies on sulfated glycopeptides from the carbohydrate-protein linkage region of chondroitin 4-sulfate proteoglycans of swarm rat chondrosarcoma. J. Biol. Chem. 263, 10168-10174 (1988)

8. Lauder, R.M., Huckerby, T.N., Nieduszynski, I.A.: Increased incidence of unsulphated and 4-sulphated residues in the chondroitin sulphate linkage region observed by high-pH 
anion-exchange chromatography. Biochem. J. 347, 339-348 (2000)

9. Ueno, M., Yamada, S., Zako, M., Bernfield, M., Sugahara, K.: Structural characterization of heparan sulfate and chondroitin sulfate of syndecan-1 purified from normal murine mammary gland epithelial cells. J. Biol. Chem. 276, 29134-29140 (2001)

10. Gulberti, S., Lattard, V., Fondeur, M., Jacquinet, J.C., Mulliert, G., Netter, P., Magdalou, J., Ouzzine, M., Fournel-Gigleux, S.: Phosphorylation and sulfation of oligosaccharide substrates critically influence the activity of human $\beta 1$,4-galactosyltransferase 7 (GalT-I) and 11,3-glucuronosyltransferase I (GlcAT-I) involved in the biosynthesis of the glycosaminoglycan-protein linkage region of proteoglycans. J. Biol. Chem. 280, 1417-1425 (2005)

11. Tone, Y., Pedersen, L.C., Yamamoto, T., Izumikawa, T., Kitagawa, H., Nishihara, J., Tamura, J., Negishi, M., Sugahara, K.: 2-O-Phosphorylation of xylose and 6-O-sulfation of galactose in the protein linkage region of glycosaminoglycans influence the glucuronyltransferase-I activity involved in the linkage region synthesis. J. Biol. Chem. 283, 16801-16807 (2008)

12. Ito, Y., Hikino, M., Yajima, Y., Mikami, T., Sirko, S., von Holst, A., Faissner, A., Fukui, S., Sugahara, K.: Structural characterization of the epitopes of the monoclonal antibodies 473HD, CS-56, and MO-225 specific for chondroitin sulfate D-type using the oligosaccharide library. Glycobiology 15, 593-603 (2005)

13. Pothacharoen, P., Kalayanamitra, K., Deepa, S.S., Fukui, S., Hattori, T., Fukushima, N., 
Hardingham, T., Kongtawelert, P., Sugahara, K.: Two related but distinct chondroitin sulfate mimetope octasaccharide sequences recognized by monoclonal antibody WF6. J. Biol. Chem. 282, 35232-35246 (2007)

14. Deepa, S.S., Kalayanamitra, K., Ito, Y., Kongtawelert, P., Fukui, S., Yamada, S., Mikami, T., Sugahara, K.: Novel sulfated octa- and decasaccharides from squid cartilage chondroitin sulfate E. Biochemistry 46, 2453-2465 (2007)

15. Deepa, S.S., Yamada, S., Fukui, S., Sugahara, K.: Structural determination of novel sulfated octasaccharides isolated from chondroitin sulfate of shark cartilage and their application for characterizing monoclonal antibody epitopes. Glycobiology 17, 631-645 (2007)

16. Purushothaman, A., Fukuda, J., Mizumoto, S., ten Dam, G.B., van Kuppevelt, T.H., Kitagawa, H., Mikami, T., Sugahara, K.: Functions of chondroitin sulfate/dermatan sulfate chains in brain development. J. Biol. Chem. 282, 19442-19452 (2007)

17. Maeda, N., He, J., Yajima, Y., Mikami, T., Sugahara, K., Yabe, T.: Heterogeneity of the chondroitin sulfate portion of phosphacan/6B4 proteoglycan regulates its binding affinity for pleiotrophin/heparin binding growth-associated molecule. J. Biol. Chem. 278, 35805-35811 (2003)

18. Pothacharoen, P., Siriaunkgul, S., Ong-Chai, S., Supabandhu, J., Kumja, P., Wanaphirak, C., Sugahara, K., Hardingham, T., Kongtawelert, P.: Raised serum chondroitin sulfate epitope level in ovarian epithelial cancer. J. Biochem. 140, 517-524 (2006) 
19. ten Dam, G.B., van de Westerlo, E.M., Purushothaman, A., Stan, R.V., Bulten, J., Sweep, F.C., Massuger, L.F., Sugahara, K., van Kuppevelt, T.H.: Antibody GD3G7 selected against embryonic glycosaminoglycans defines chondroitin sulfate-E domains highly up-regulated in ovarian cancer and involved in vascular endothelial growth factor binding. Am. J. Pathol. 171, $1324-1333(2007)$

20. Nakagawa, H., Hama, Y., Sumi, T., Li, S.C., Maskos, K., Kalayanamitra, K., Mizumoto, S., Sugahara, K., Li, Y.T.: Occurrence of a nonsulfated chondroitin proteoglycan in the dried saliva of Collocalia swiftlets (edible bird's-nest). Glycobiology 17, 157-164 (2007)

21. Sugahara, K., Masuda, M., Harada, T., Yamashina, I., de Waard, P., Vliegenthart, J.F.G.: Structural studies on sulfated oligosaccharides derived from the carbohydrate-protein linkage region of chondroitin sulfate proteoglycans of whale cartilage. Eur. J. Biochem. 202, 805-811 $(1991)$

22. Esko, J.D., Stewart, T.E., Taylor, W.H.: Animal cell mutants defective in glycosaminoglycan biosynthesis. Proc. Natl. Acad. Sci. U.S.A. 82, 3197-3201 (1985)

23. Sakaguchi, H., Watanabe, M., Ueoka, C., Sugiyama, E., Taketomi, T., Yamada, S., Sugahara, K.: Isolation of reducing oligosaccharide chains from the chondroitin/dermatan sulfate-protein linkage region and preparation of analytical probes by fluorescent labeling with 2-aminobenzamide. J. Biochem. 129, 107-118 (2001)

24. Rio, S., Beau, J.M., Jacquinet, J.C.: Synthesis of sulfated and phosphorylated glycopeptides from 
the carbohydrate-protein linkage region of proteoglycans. Carbohydr. Res. 255, 103-124 (1994)

25. Sugahara, K., Ohi, Y., Harada, T., de Waard, P., Vliegenthart, J.F.G.: Structural studies on sulfated oligosaccharides derived from the carbohydrate-protein linkage region of chondroitin 6-sulfate proteoglycans of shark cartilage. J. Biol. Chem. 267, 6027-6035 (1992)

26. de Waard, P., Vliegenthart, J.F.G., Harada, T., Sugahara, K.: Structural studies on sulfated oligosaccharides derived from the carbohydrate-protein linkage region of chondroitin 6-sulfate proteoglycans of shark cartilage. J. Biol. Chem. 267, 6036-6043 (1992)

27. Ludwigs, U., Elgavish, A., Esko, J.D., Meezan, E., Rodén, L.: Reaction of unsaturated uronic acid residues with mercuric salts. Biochem. J. 245, 795-804 (1987)

28. Kusche, M., Lindahl, U., Enerbäck, L., Rodén, L.: Identification of oversulphated galactosaminoglycans in intestinal-mucosal mast cells of rats infected with the nematode worm Nippostrongylus brasiliensis. Biochem. J. 253, 885-893 (1988)

29. Yoshida, K., Arai, M., Kohno, Y., Maeyama, K., Miyazono, H., Kikuchi, H., Morikawa, K., Tawada, A., Suzuki, S.: Activity of bacterial eliminases towards dermatan sulphates and dermatan sulphate proteoglycan. In: Scott, J.E. (ed.) Dermatan sulphate proteoglycans pp. 55-70, Portland Press, London

30. Yamagata, T., Saito, H., Habuchi, O., Suzuki, S.: Purification and properties of bacterial chondroitinases and chondrosulfatases. J. Biol. Chem. 243, 1523-1535 (1968)

31. Bitter, T., Muir, H.M.: A modified uronic acid carbazole reaction. Anal. Biochem. 4, 330-334 
32. May, R.J., Beenhouwer, D.O., Scharff, M.D.: Antibodies to keyhole limpet hemocyanin cross-react with an epitope on the polysaccharide capsule of Cryptococcus neoformans and other carbohydrates. J. Immunol. 171, 4905-4912 (2003)

33. Heinegård, D.: Hyaluronidase digestion and alkaline treatment of bovine tracheal cartilage proteoglycans. Biochim. Biophys. Acta 285, 193-207 (1972)

34. Sugahara, K., Kojima, T.: Specificity studies of bacterial sulfatases by means of structurally defined sulfated oligosaccharides isolated from shark cartilage chondroitin sulfate D. Eur. J. Biochem. 239, 865-870 (1996)

35. Nakanishi, M., Moriyama, A., Narita, Y., Sasaki, M.: Aminopeptidase M from human liver. J. Biochem. 106, 818-825 (1989)

36. Pétra, P.H.: Bovine procarboxypeptidase and carboxypeptidase A. Methods Enzymol. 19, 460-503 (1970)

37. Moses, J., Oldberg, ̊̊., Fransson, L.- $\AA$.: Initiation of galactosaminoglycan biosynthesis. Separate galactosylation and dephosphorylation pathways for phosphoxylosylated decorin protein and exogenous xyloside. Eur. J. Biochem. 260, 879-884 (1999)

38. Kitagawa, H., Tsutsumi, K., Ikegami-Kuzuhara, A., Nadanaka, S., Goto, F., Ogawa, T., Sugahara, K.: Sulfation of the galactose residues in the glycosaminoglycan-protein linkage region by recombinant human chondroitin 6-O-sulfotransferase-1. J. Biol. Chem. 283, 27438-27443 (2008) 
39. Kitagawa, H., Tsutsumi, K., Ujikawa, M., Goto, F., Tamura, J., Neumann, K. W., Ogawa, T., Sugahara, K.: Regulation of chondroitin sulfate biosynthesis by specific sulfation. Glycobiology 7, 531-537 (1997)

40. Lidholt, K., Fjelstad, M., Lindahl, U., Goto, F., Ogawa, T., Kitagawa, H., Sugahara, K.: Assessment of glycosaminoglycan-protein linkage tetrasaccharides as acceptors for GalNAc- and GlcNAc-transferases from mouse mastocytoma. Glycoconj. J. 14, 737-742 (1997)

41. Lauder, R.M., Huckerby, T.N., Brown, G.M., Bayliss, M.T., Nieduszynski, I.A.: Age-related changes in the sulphation of the chondroitin sulphate linkage region from human articular cartilage aggrecan. Biochem. J. 358, 523-528 (2001)

42. Yamada, S., Oyama, M., Kinugasa, H., Nakagawa, T., Kawasaki, T., Nagasawa, S., Khoo, K.-H., Morris, H.R., Dell, A., Sugahara, K.: The sulphated carbohydrate-protein linkage region isolated from chondroitin 4-sulphate chains of inter- $\alpha$-trypsin inhibitor in human plasma. Glycobiology $\mathbf{5}$, 335-341 (1995)

43. Koike, T., Izumikawa, T., Tamura, J., Kitagawa, H.: FAM20B is a kinase that phosphorylates xylose in the glycosaminoglycan-protein linkage region. Biochem. J. 421, 157-162 (2009)

44. Sugumaran, G., Silbert, J.E.: Subfractionation of chick embryo epiphyseal cartilage Golgi. J. Biol. Chem. 266, 9565-9569 (1991)

45. Sugumaran, G., Katsman, M., Silbert, J.E.: Subcellular co-localization and potential interaction of glucuronosyltransferases with nascent proteochondroitin sulphate at Golgi sites of chondroitin 
synthesis. Biochem. J. 329, 203-208 (1998)

46. Prydz, K., Dalen, K.T.: Synthesis and sorting of proteoglycans. J. Cell Sci. 113, 193-205 (2000)

47. Esko, J.D., Weinke, J.L., Taylor, W.H., Ekborg, G., Rodén L., Anantharamaiah, G., Gawish, A.: Inhibition of chondroitin and heparan sulfate biosynthesis in Chinese hamster ovary cell mutants defective in galactosyltransferase I. J. Biol. Chem. 262, 12189-12195 (1987)

48. Bai, X., Wei, G., Sinha, A., Esko J.D.: Chinese hamster ovary cell mutants defective in glycosaminoglycan assembly and glucuronosyltransferase I. J. Biol. Chem. 274, 13017-13024 (1999)

49. Esko, J.D., Zhang, L.: Influence of core protein sequence on glycosaminoglycan assembly. Curr. Opin. Struct. Biol. 6, 663-670 (1996)

50. Kolset, S.O., Tveit, H.: Serglycin - structure and biology. Cell. Mol. Life Sci. 65, 1073-1085 (2008)

51. Fransson, L.-Å.: Structure and function of cell-associated proteoglycans. Trends Biochem. Sci. 12, 406-411 (1987)

52. Nadanaka, S., Kitagawa, H., Sugahara K.: Demonstration of the immature glycosaminoglycan tetrasaccharide sequence GlcA $\beta 1-3 \mathrm{Gal} \beta 1-3 \mathrm{Gal} \beta 1-4 \mathrm{Xyl}$ on recombinant soluble human $\alpha$-thrombomodulin. J. Biol. Chem. 273, 33728-33734 (1998) 


\section{Figure legends}

Fig. 1 Reactivity of the antibody 4E1/D6 toward various PG preparations. The reactivity of the antibody 4E1/D6 with various PGs was analyzed by ELISA. PGs from salmon nasal cartilage, rayfish cartilage, bird nest, chicken cartilage, bovine nasal cartilage, whale cartilage (10 $\mu \mathrm{g}$ each) and the linkage hexasaccharide peptide (hexa-pep) fraction derived from shark cartilage CS ( $0.5 \mathrm{ug})$ were individually immobilized to the wells, and processed for incubation with 4E1/D6 followed by alkaline phosphatase-linked goat anti-mouse $\operatorname{Ig}(\mathrm{G}+\mathrm{M})$ (diluted 3,000-fold). Bound antibodies were detected by the addition of $p$-nitrophenylphosphate as a substrate. The reactivity is given relative to the linkage hexasaccharide-peptide fraction from shark cartilage CS.

Fig. 2 Reactivity of the antibody 4E1/D6 toward various linkage oligosaccharide-peptide fractions. The linkage hexa-, penta-, and tetrasaccharide-peptide fractions derived from shark cartilage CS and the linkage hexasaccharide-peptide fraction from whale cartilage CS $(0.5 \mu \mathrm{g}$ each $)$ were immobilized to the wells, and the reactivity of 4E1/D6 to the immobilized fractions was analyzed by ELISA as described in the legend to Figure 1. The assay was performed in duplicate and values represent the mean \pm S.D. The reactivity is given relative to the linkage hexasaccharide-peptide fraction from shark cartilage CS.

Fig. 3 Reactivity of the antibody 4E1/D6 toward the linkage hexasaccharide-peptide fraction treated 
with alkali or peptidases. The linkage hexasaccharide-peptide (hexa-pep) fraction from shark cartilage CS was treated with alkali, or digested with aminopeptidase or carboxypeptidase. Each sample was used as an inhibitor (4 nmol each) for the binding of 4E1/D6 to the immobilized un-treated linkage hexasaccharide-peptide fraction $(0.5 \mu \mathrm{g})$ for the competitive ELISA. The un-treated linkage hexasaccharide-peptide fraction $(4 \mathrm{nmol})$ was also used as a control inhibitor. Bound antibodies were visualized as described in the legend to Figure 1. This assay was performed in duplicate, and all values are expressed as a percentage of the reactivity observed without inhibitors and represent the mean \pm S.D.

Fig. 4 Reactivity of the antibody 4E1/D6 toward the linkage hexasaccharide-peptide fraction treated with phosphatase or chondro-4-sulfatase. The linkage hexasaccharide-peptide fraction (500 pmol each) was treated with alkali phosphatase or chondro-4-sulfatase and each digest was immobilized to the well. The reactivity of 4E1/D6 toward the digest was analyzed by ELISA. Bound antibodies were visualized as described in the legend to Figure 1 . The reactivity is given relative to the linkage hexasaccharide-peptide fraction from shark cartilage CS. The assay was performed in duplicate and values represent the mean \pm S.D.

Fig. 5 Action of chondro-4-sulfatase on the structurally defined linkage hexasaccharide. The structurally defined linkage hexasaccharide, 
$\Delta$ HexA-GalNAc(4-O-sulfate)-GlcA-Gal(4-O-sulfate)-Gal-Xyl (500 pmol) was analyzed before (A) and after (B) digestion with chondro-4-sulfatase by anion-exchange HPLC on an amine-bound silica column using a linear gradient of $\mathrm{NaH}_{2} \mathrm{PO}_{4}$ from $16 \mathrm{mM}$ to $540 \mathrm{mM}$ over 60 min. The peaks were monitored by measuring UV-absorbance at $232 \mathrm{~nm}$. Closed and open arrows indicate the positions of authentic standard linkage hexasaccharides $\Delta$ HexA-GalNAc(4-O-sulfate)-GlcA-Gal(4-O-sulfate)-Gal-Xyl and $\Delta$ HexA-GalNAc-GlcA-Gal-Gal-Xyl, respectively. Treatment with chondro-4-sulfatase caused a shift in the position of the former to that of the latter, indicating the removal of the two sulfate groups.

Fig. 6 The predicted structure required for the recognition by the antibody 4E1/D6. The epitope structure recognized by 4E1/D6 was predicted based on the data obtained in this study. The 6-O-sulfation of the penultimate Gal residue from the reducing terminus (marked by an asterisk) seems to be necessary for recognition by $4 \mathrm{E} 1 / \mathrm{D} 6$. The requirement of $6-O$-sulfation on the nonreducing terminal GalNAc or the internal Gal residue has not been confirmed. $\mathrm{R}_{1}$ and $\mathrm{R}_{2}$ indicate the amino acid residues adjacent to the serine residue, which remained uncleaved after digestion with actinase E.

Fig. 7 Interaction of 4E1/D6 with two CHO cell lines. The reactivity of 4E1/D6 toward two CHO cell lines, wild type (CHO-K1) (A) and xylosyltransferase-deficient (pgsA) (B) cells, was assessed 
by immunofluorescence flow cytometry. A HS-specific monoclonal antibody (F58/10E4) was used as a control. Light gray and dark gray histograms represent the 4E1/D6 and F58-10E4-binding, respectively, as detected with Alexa Fluor $488^{\circledR}$-conjugated anti-mouse IgM antibody. Empty histograms show the background fluorescence. 
Click here to download high resolution image

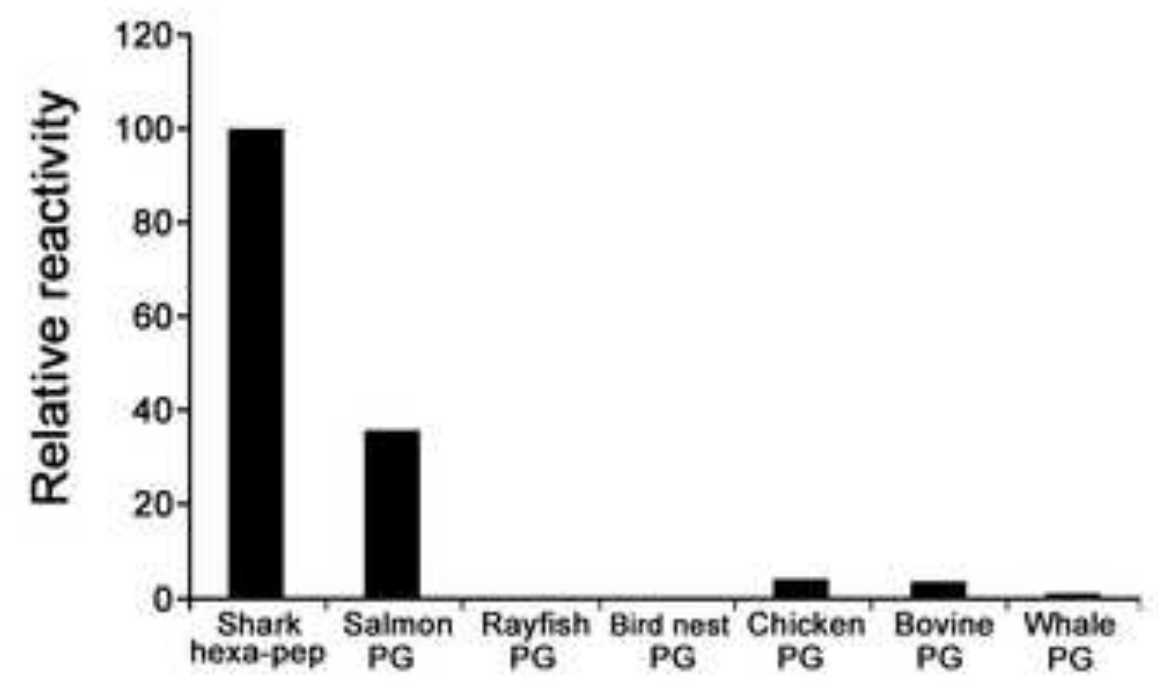


Click here to download high resolution image

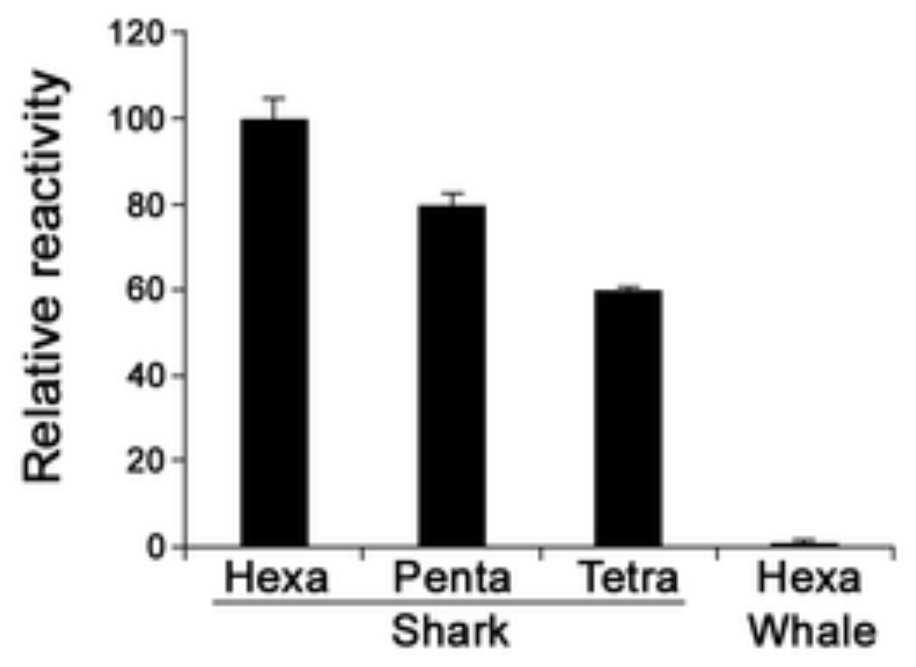


Click here to download high resolution image

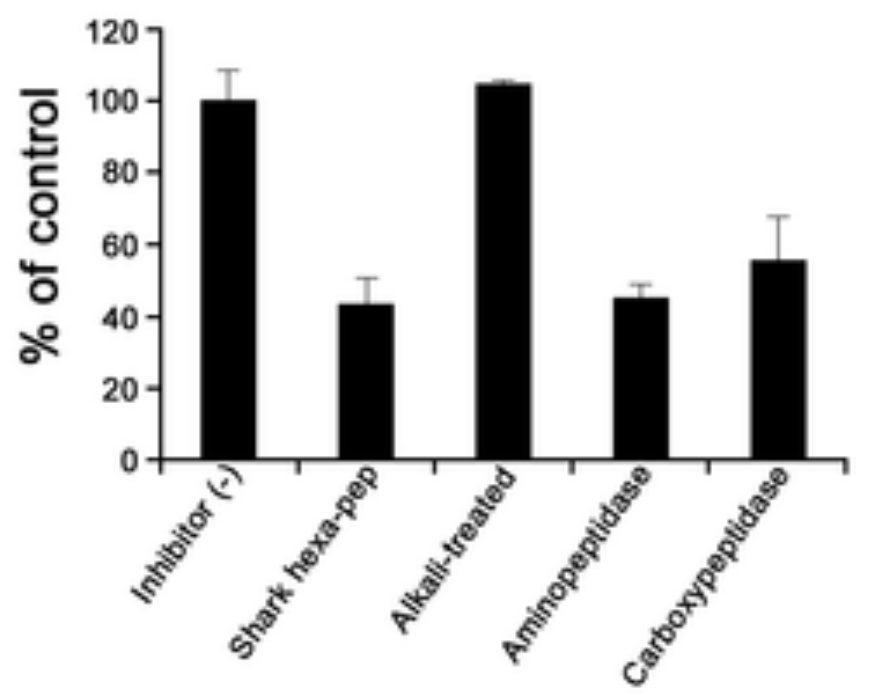


Click here to download high resolution image

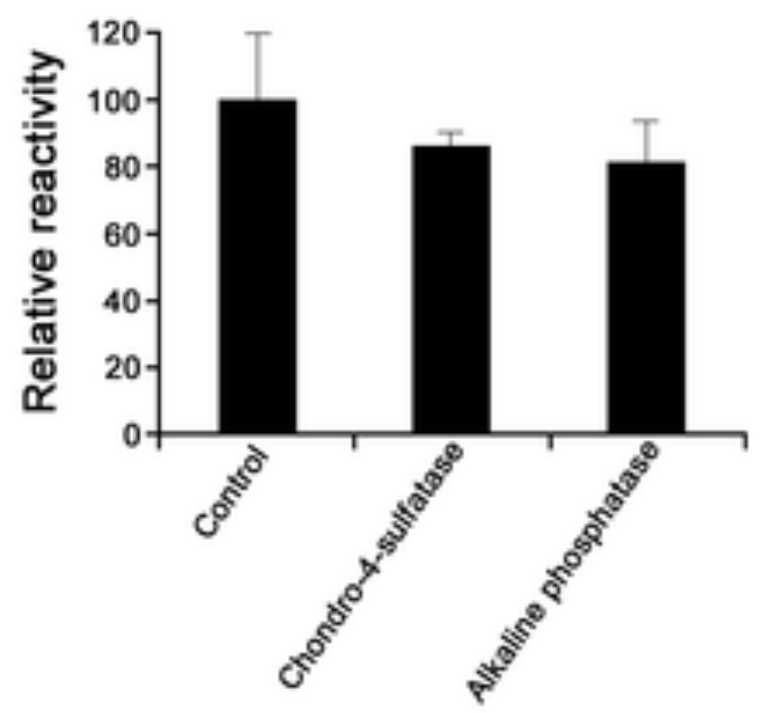


Figure5

Click here to download high resolution image

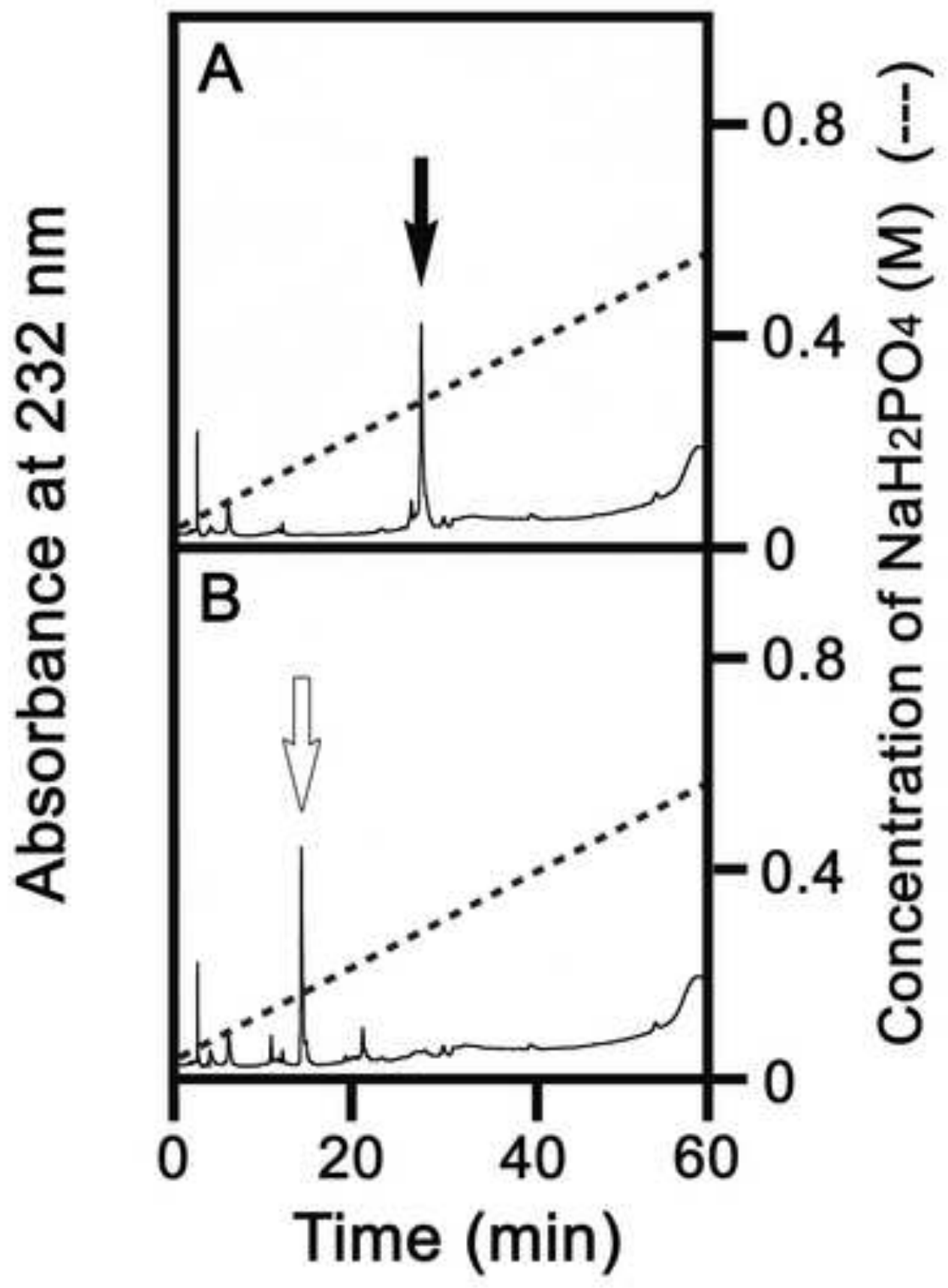


Click here to download high resolution image

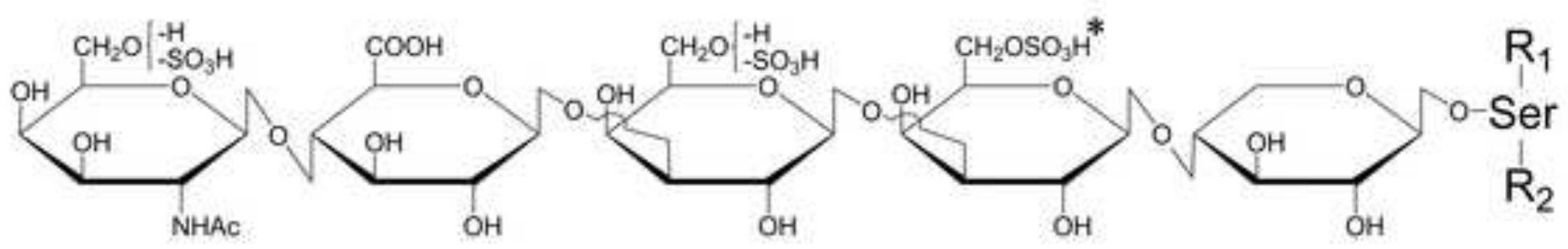




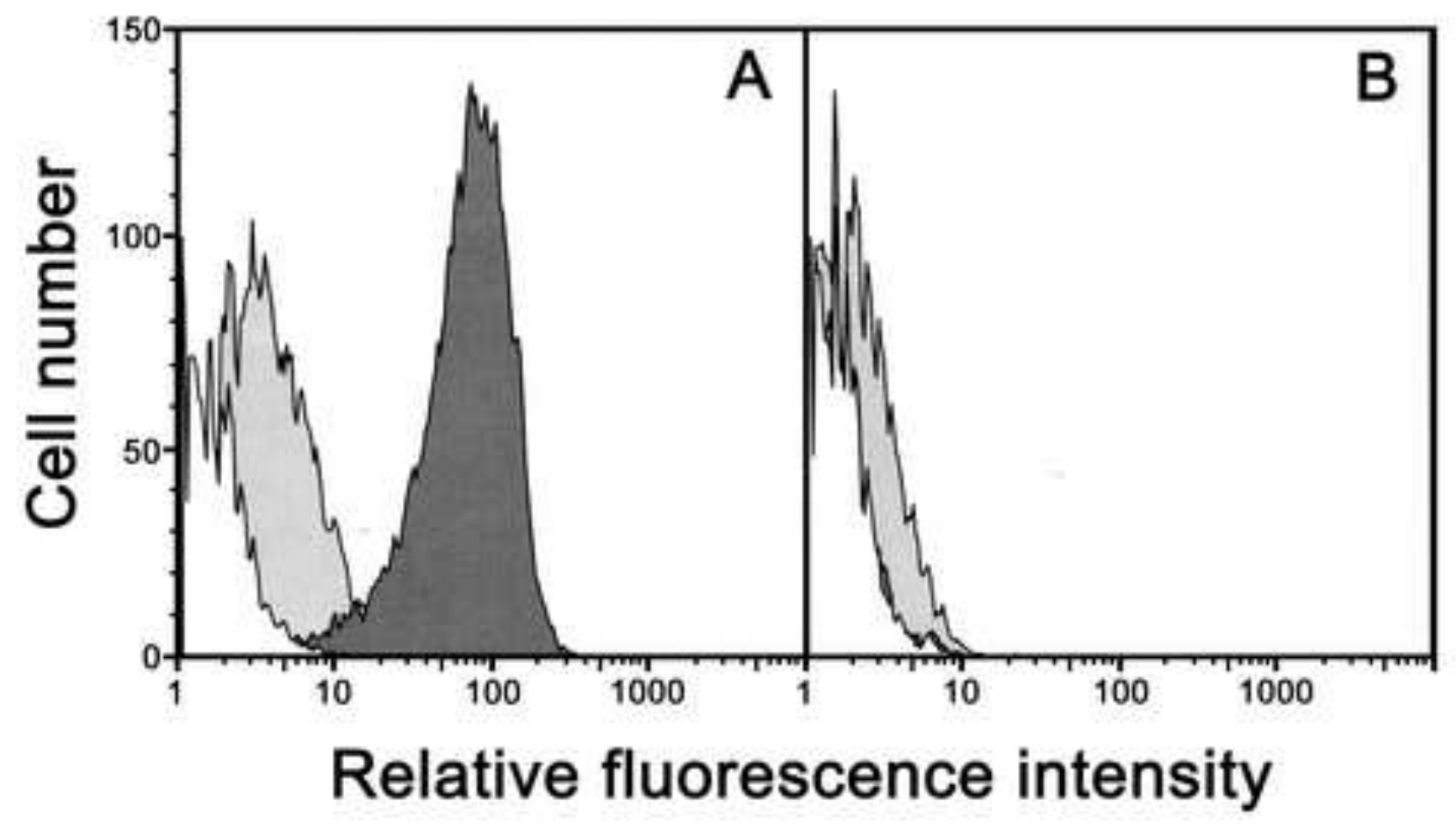


Table 1. Structure of the major components in the linkage hexasaccharide fractions purified from CS of shark cartilage and whale cartilage

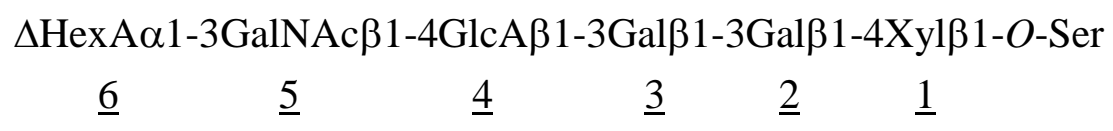

CS from shark cartilage ${ }^{\mathrm{a}}$

\begin{tabular}{|c|c|c|c|c|c|c|}
\hline \multicolumn{6}{|c|}{ Modifications $^{\mathrm{b}}$} & \multirow{2}{*}{$\begin{array}{c}\text { Proportion }^{\mathrm{c}} \\
(\mathrm{mol} \%)\end{array}$} \\
\hline$\underline{6}$ & $\underline{5}$ & $\underline{4}$ & $\underline{3}$ & $\underline{2}$ & $\underline{1}$ & \\
\hline - & - & - & - & - & - & 13.1 \\
\hline- & $6 \mathrm{~S}$ & - & - & - & - & 8.3 \\
\hline- & $4 \mathrm{~S}$ & - & - & - & - & 2.1 \\
\hline- & - & - & - & - & $2 \mathrm{P}$ & 6.7 \\
\hline- & $6 \mathrm{~S}$ & - & - & - & $2 \mathrm{P}$ & 3.4 \\
\hline- & - & - & - & $6 \mathrm{~S}$ & - & 5.3 \\
\hline- & $6 \mathrm{~S}$ & - & - & $6 \mathrm{~S}$ & - & 4.8 \\
\hline- & $4 \mathrm{~S}$ & - & - & $6 \mathrm{~S}$ & - & 1.5 \\
\hline- & - & - & $6 \mathrm{~S}$ & $6 \mathrm{~S}$ & - & 5.5 \\
\hline- & $6 \mathrm{~S}$ & - & $6 S$ & $6 \mathrm{~S}$ & - & 37.4 \\
\hline- & $4 \mathrm{~S}$ & - & $6 \mathrm{~S}$ & $6 \mathrm{~S}$ & - & 9.1 \\
\hline- & $6 \mathrm{~S}$ & 一 & $4 \mathrm{~S}$ & $6 \mathrm{~S}$ & - & 1.1 \\
\hline- & $4 \mathrm{~S}$ & - & $4 \mathrm{~S}$ & $6 \mathrm{~S}$ & - & 1.6 \\
\hline
\end{tabular}

CS from whale cartilage ${ }^{\mathrm{d}}$

\begin{tabular}{|c|c|c|c|c|c|c|}
\hline \multicolumn{6}{|c|}{ Modifications $^{\mathrm{b}}$} & \multirow{2}{*}{$\begin{array}{c}\text { Proportion }^{c} \\
(\mathrm{~mol} \%)\end{array}$} \\
\hline$\underline{6}$ & $\underline{5}$ & $\underline{4}$ & $\underline{3}$ & $\underline{2}$ & $\underline{1}$ & \\
\hline- & - & - & - & - & - & 21 \\
\hline - & $6 \mathrm{~S}$ & - & - & - & - & 16 \\
\hline- & $4 \mathrm{~S}$ & - & - & - & - & 36 \\
\hline - & $4 \mathrm{~S}$ & - & $4 S$ & - & - & 27 \\
\hline
\end{tabular}

${ }^{\mathrm{a}}$ Data are from Sugahara et al. 1992 [25] and de Waard et al. [26].

${ }^{\mathrm{b}}$ The modifications in each monosaccharide residue are shown in the table. The numbers refer to the corresponding residues in the linkage structures shown above. $4 \mathrm{~S}, 6 \mathrm{~S}$, and $2 \mathrm{P}$ stand for $4-O$-sulfate, 6-O-sulfate, and 2-O-phosphate, respectively.

${ }^{c}$ The proportion of each structure is expressed as a molar percentage of the total linkage hexasaccharide fraction.

${ }^{\mathrm{d} D a t a}$ are from Sugahara et al. 1991 [21]. 